\title{
Application of Dual-Source-Computed Tomography in Pediatric Cardiology in Children Within the First Year of Life
}

\section{Einsatz der Dual-Source-Computertomografie in der Kinder- kardiologie bei Kindern im ersten Lebensjahr}

Authors

Affiliations

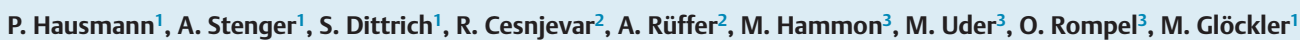

Pediatric Cardiology, Friedrich-Alexander-University Erlangen-Nürnberg (FAU), Germany

Congenital Heart Surgery, Friedrich-Alexander-University Erlangen-Nürnberg (FAU), Germany

Radiology, Friedrich-Alexander-University Erlangen-Nürnberg (FAU), Germany
Key words

- heart

- CT-angiography

- surgery

received $\quad 16.5 .2015$

accepted $\quad 13.10 .2015$

Bibliography

Dol http://dx.doi.org/

10.1055/s-0041-108912

Published online: 2016

Fortschr Röntgenstr 2016; 188:

179-187 @ Georg Thieme

Verlag KG Stuttgart · New York ISSN 1438-9029

\section{Correspondence}

\section{Dr. Martin Glöckler}

Kinderkardiologie,

Universitätsklinikum Erlangen

Loschgestraße 15

91054 Erlangen

Germany

Tel.: ++ 49/9131/8533750

Fax: ++49/9131/8535987

martin.gloeckler@uk-

erlangen.de

\section{Abstract}

$\nabla$

Purpose: To assess fields of application and value of dual source computed tomography (DSCT) for diagnostics and therapy in patients with congenital heart disease during their first year of life. Evaluation of image quality, surgical use and radiation exposure of 2 nd and $3 \mathrm{rd}$ generation DSCT.

Materials and methods: DSCT was applied in 118 cases between January 2012 and October 2014 for diagnostics of congenital heart defects. 2nd generation was used in 91 cases until April 2014 and 3 rd generation in 27 cases during the period thereafter. $3 \mathrm{D}$ reconstructions of the image data were created for clinical diagnostics and planning of interventions. Image quality was assessed using a 4-pointscale. The visibility of the mammary arteries was analyzed, and signal-to-noise-ratio (SNR) and contrast-to-noise-ratio (CNR) were calculated. The usefulness of 3D-reconstructions for surgical planning was rated using a 5-pointscale. Radiation exposure and contrast dye consumption were determined. All cases were analyzed retrospectively.

Results: DSCT was successfully used in 118 cases. All image data obtained were interpretable. More than 60 percent of cases did not show any artifacts. The mammary arteries were visible down to the diaphragmatic arch in more than 80 percent of cases. Diagnostic value and surgical benefit were evaluated as "useful" or as "essential" in all cases. Median radiation dose was $0.4 \mathrm{mSv}$ and $0.27 \mathrm{mSv}$ for the 2 nd and 3 rd generation DSCT, respectively. Consumption of contrast dye was $2 \mathrm{ml} / \mathrm{kg}$ in all cases.

Conclusion: DSCT is a modern and extremely helpful technique for diagnostics and planning of interventions in patients with complex congenital heart defects. Extracardiac vascular structures in particular can be depicted threedimensionally at high resolution. The use of iterative reconstruction with 3 rd generation DSCT yielded image quality similar to that of 2nd generation DSCT at considerably reduced radiation exposure level compared to 2 nd generation DSCT. 3 rd generation DSCT is a low risk, accurate and extremely fast technique for diagnosing unstable patients with CHD.

Key points:

- Expanded scope of indications for DSCT in diagnosing critically ill infants

- Effective radiation dose is considerably lower than $0.5 \mathrm{mSv}$

- Extremely rapid image acquisitions with high image quality

- Possibility of optimized 3D-based surgical planning

Citation Format:

- Hausmann P, Stenger A, Dittrich S etal. Application of Dual-Source-Computed Tomography in Pediatric Cardiology in Children Within the First Year of Life. Fortschr Röntgenstr 2016; 188: 179-187

\section{Zusammenfassung}

$\nabla$

Ziel: Evaluation von Einsatzmöglichkeiten und Nutzen der Dual-Source-Computertomografie (DSCT) bei Säuglingen mit angeborenem Herzfehler (AHF). Bewertung von Bildqualität, chirurgischen Stellenwert und Strahlenbelastung der 2. und 3. Generation DSCT.

Material und Methoden: Die DSCT wurde zwischen 2012 und 2014 in 118 Fällen zur Diagnostik AHF angewendet. Bis April 2014 wurde die 2. Generation DSCT in 91 Fällen und die 3. Generation im darauffolgenden Zeitraum in 27 Fällen durchgeführt. Die gewonnenen Bilddaten wurden zur Diagnostik und Eingriffsplanung dreidimensional (3 D) aufbereitet. Zur Evaluation der Bildqualität 
wurde eine 4-Punkte-Skala verwendet. Die Visualisierung der A. mammaria, das Signal-Rausch-Verhältnis (SNR) sowie das Kontrast-Rausch-Verhältnis (CNR) wurden ausgewertet. Der chirurgische Nutzen der DSCT wurde anhand einer 5-Punkte-Skala beurteilt. Die Strahlendosis und der Kontrastmittelverbrauch wurden bestimmt.

Ergebnisse: Alle gewonnenen Bilddaten waren interpretierbar. In über $60 \%$ der Fälle waren die Bilddaten artefaktfrei. Die A. mammaria war in über $80 \%$ der Fälle mindestens bis zur Zwerchfellkuppel darstellbar. Die diagnostische Wertigkeit und der chirurgische Nutzen wurden immer als „nützlich“ oder „essenziell“ bezeichnet. Die Strahlenbelastung betrug bei der 2. Generation im Median 0,4 mSv und bei der 3. Generation 0,27 mSv. Der Kontrastmittelverbrauch war stets $2 \mathrm{ml} / \mathrm{kg}$.

Schlussfolgerung: Die DSCT ist ein modernes, überaus hilfreiches Verfahren zur Diagnostik und Eingriffsplanung bei Patienten mit komplexen AHF. Insbesondere extrakardiale, vaskuläre Strukturen lassen sich in hoher Auflösung 3 D darstellen. Durch die iterative Rekonstruktion der Daten in der 3. Generation DSCT kann bei erheblich geringerer Strahlenbelastung im Vergleich zur 2. Generation DSCT eine gleich gute Bildqualität erzielt werden. Die 3. Generation DSCT ist damit ein schonendes, exaktes und extrem schnelles Verfahren zur Diagnostik instabiler kardiologischer Patienten.

\section{Introduction}

\section{$\nabla$}

With an incidence of just over $1 \%$ [1], congenital heart defects are among the most common congenital malformations and are responsible for a large percentage of postnatal mortality and morbidity [2]. Critical heart defects (accounting for approximately $15 \%$ of all heart defects) are defined as any that become symptomatic in the first month of life and, if left untreated, result in death in the first year of life [3]. Mortality can be lowered using modern surgical techniques [4], and even highly complex heart defects can be managed with good prognosis through early surgical or interventional correction [5]. However, surgical correction of especially complex heart defects with the patient on a heart-lung machine remains hazardous and entails a high risk of peri- and postoperative complications $[5,6]$. To minimize these risks, the surgery must be performed expediently and kept as brief as possible. For this purpose, the surgical team must have precise and comprehensive knowledge of the patient's anatomical situation. Intraoperative amendment of diagnoses, change in strategy and thereby extended surgery times and unnecessary dissection must be avoided through accurate diagnosis based on medical imaging in advance [2-6]. Indepth familiarity with the anatomical structures as well as their spatial relation to one another is essential for planning the intervention [7].

While echocardiography is the medical imaging gold standard [8], it is inadequate when used as sole imaging technique in complex cases. It has a limited viewing window, does not sufficiently image airways and extracardiac structures and does not permit comprehensive 3D-representation [9]. In the field of pediatric cardiology, invasive heart catheter examinations are currently used primarily for interventional procedures and no longer as a diagnostic tool [10]. For advanced primary diagnosis of congenital heart defects, cross-sectional imaging modalities such as magnetic resonance imaging (MRI) and computed tomography
(CT), which saw rapid technical advancement in the last decade, are increasingly popular $[11,12]$. MRI enables cardiac imaging with generally sufficient spatial resolution and delivers valuable hemodynamic information, even in newborns with congenital heart defects. However, its lengthy examination time and generally required endotracheal anesthesia are risky for critically ill infants [13-15]. CT is less invasive, offers high temporal and spatial resolution and requires no sedation or anesthesia in most cases. With the aid of 3D-representation, it allows improved visualization of cardiac structures for surgical planning [16]. Modern dual-source-CT (DSCT) delivers precise anatomical information within a single cardiac cycle, even in infants with tachycardia [17]. Until now, computed tomography was used cautiously in pediatric cardiology and recommended only as a supplemental procedure in exceptional cases [11]. In our clinical opinion, however, DSCT justifies the expanded use of computed tomography in pediatric cardiology with its excellent image quality, very rapid data acquisition and, at the same time, lower radiation exposure. To evaluate the indication for modern DSCT, we therefore retrospectively assessed $118 \mathrm{CT}$ examinations, assessing image quality and radiation exposure as well as the significance of the image data for planning the surgery.

\section{Patients and methodology}

$\nabla$

Between January 2012 and October 2014, our department performed preoperative DSCT on 142 patients with congenital heart defects. Of this number, all patients who had not yet reached their first birthday at the time of examination were included in the study $(\mathrm{n}=118)$. Among this group, $91 \mathrm{pa}-$ tients were examined using $2^{\text {nd }}$ generation DSCT (SOMATOM Definition Flash, Siemens Healthcare, Forchheim, Germany) through April 2014, while 27 were examined using $3^{\text {rd }}$ generation DSCT (SOMATOM Force, Siemens Healthcare, Forchheim, Deutschland) between February 2014 and October 2014. DSCT was always used if there were any remaining questions for surgical planning after echocardiography had been performed.

The examinations were performed in high-pitch-mode and with prospective ECG triggering (acquisition at $40-60 \%$ of the blood pressure interval) and automatic illumination control (CareDose 4D, Siemens AG, Erlangen, Germany). The examinations performed with $2^{\text {nd }}$ generation DSCT employed a tube voltage of $80 \mathrm{kV}$, a reference tube current of $400 \mathrm{mAs}$, a pitch of 3.4 and a slice collimation of $2 \times 128 \times 0.6 \mathrm{~mm}$. The examinations performed with $3^{\text {rd }}$ generation DSCT employed a tube voltage of $70 \mathrm{kV}$, a reference tube current of $400 \mathrm{mAs}$, a pitch of 3.2 and a slice collimation of $2 \times 192 \times 0.6 \mathrm{~mm}$. Reconstruction increment was $0.6 \mathrm{~mm}$ for both generations. For reconstruction, the $2^{\text {nd }}$ generation DSCT employed the convolution kernel B26 $\mathrm{f}$ (body sharpness level 26 fine), while the $3^{\text {rd }}$ generation employed the convolution kernel Bv40 (body vascular sharpness level 40).

The examinations were performed without mechanical ventilation and manipulation of heart rate for image optimization. The patients were supposed to lie still in the phase between the topogram, contrast agent injection and start of CT imaging. In $9.3 \%$ of cases $(11 / 118)$ this required mild sedation by means of intravenous midazolam $(0.1 \mathrm{mg} / \mathrm{kg})$. The 
contrast agent was manually injected in all cases (Iomeprol, $2 \mathrm{ml} / \mathrm{kg}$ body weight, $300 \mathrm{mg}$ iodine/ml; Imeron 300, Bracco Imaging, Konstanz, Germany). The datasets acquired were evaluated by radiologists and then converted into $3 \mathrm{D}$ images by a pediatric radiologist for surgical planning. The 3D-reconstruction of $0.6 \mathrm{~mm}$ slices was performed using Aquarius iNtuition (TeraRecon, Inc., San Mateo, CA, USA), with those of the $3^{\text {rd }}$ generation DSCT being generated from iteratively reconstructed data (advanced modelled iterative reconstruction, ADMIRE 4) ( $\bullet$ Fig. 1). In contrast to the filtered back projection based on simpler analytical algorithms, the principle of the more complex iterative reconstruction (e.g., ADMIRE) is based on multiple simulated correction projections with multiple, consecutive computational cycles.

Demographic and clinical data as well as image data from the CT examinations were evaluated and expressed as medians with standard deviation ( $\bullet$ Table 1 ). All data were ana- lyzed retrospectively. Statistical analysis was performed using the software, "Analyse-it" (Analyse-it, United Kingdom). The Mann-Whitney U Test was applied.

The image quality of the acquired datasets was evaluated by an experienced pediatric cardiologist. In addition, image artifacts and the resolution of fine vascular structures were analyzed, and the signal-to-noise-ratio (SNR) and the contrast-to-noise-ratio (CNR) were computed as objective image quality parameters. Through analysis of the visualization of particularly fine vascular structures and image artifacts, it was possible to evaluate the image quality of the individual datasets based on a 4-point scale modified according to the European guidelines for computed tomography [18] as follows: 1 = "optimal visualization", 2 = "fully interpretable, low artifacts", 3 = "still interpretable with regard to the visibility of fine vascular structures despite artifacts", 4 = "not interpretable" ( $\bullet$ Table 2 ). For $3^{\text {rd }}$ generation
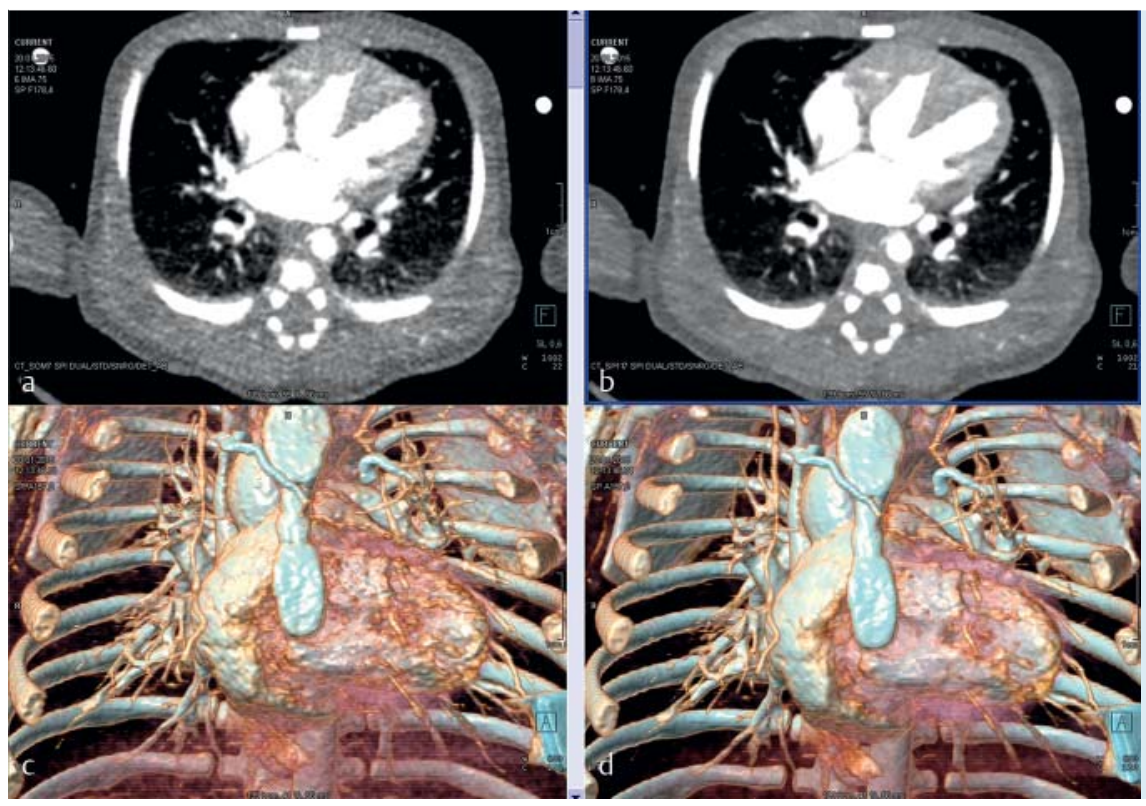

Fig. 1 Third generation of angiographic DualSource-CT of the thorax in a newborn with pulmonary atresia and ventricular septal defect (VSD). Figure a shows an axial $0.6 \mathrm{~mm}$ cross section at the level of the VSD, depicted in filtered back projection (FBP; BF40). Correspondingly, Figure $\mathbf{b}$ shows the advanced modelled iterative reconstructed image (ADMIRE level 4) with considerably less image noise. Figure $\mathbf{c}$ shows a volume-rendered reconstruction (VRT) of the native FBP, and Figure $\mathbf{d}$ shows a VRT image of ADMIRE 4, each with the same illumination setting.

Table 1 Demographic and clinical data of patients, details of CT-examinations, results of signal-to-noise-ratio (SNR) and contrast-to-noise-ratio (CNR) (number or median \pm standard deviation) and [ $11^{\text {st }} / 3^{\text {rd }}$ quartile $]$.

\begin{tabular}{|lllll}
\hline parameter & $\begin{array}{l}\text { neonates } \\
\mathbf{2}^{\text {nd }} \text { generation DSCT }\end{array}$ & $\begin{array}{l}\text { infants } \\
\mathbf{2}^{\text {nd }} \text { generation DSCT }\end{array}$ & $\begin{array}{l}\text { neonates } \\
\mathbf{3}^{\text {rd }} \text { generation DSCT }\end{array}$ & $\begin{array}{l}\text { infants } \\
\mathbf{3}^{\text {rd }} \text { generation DSCT }\end{array}$ \\
\hline number of examinations & 41 & 50 & 12 & 15 \\
\hline sex (m/f) & $18 / 23$ & $27 / 23$ & $6 / 6$ & $8 / 7$ \\
\hline age (days) & $4 \pm 3$ & $116 \pm 7.2$ & $10 \pm 7$ & $151 \pm 96$ \\
\hline weight $(\mathrm{kg})$ & $3.2 \pm 0.6$ & $5.0 \pm 2.2$ & $3.2 \pm 0.7$ & $5.3 \pm 1.9$ \\
\hline length $(\mathrm{cm})$ & $49 \pm 3$ & $58 \pm 9$ & $49 \pm 3$ & $62 \pm 10$ \\
\hline body surface $\left(\mathrm{kg} / \mathrm{m}^{2}\right)$ & $0.2 \pm 0.03$ & $0.3 \pm 0.08$ & $0.2 \pm 0.03$ & $0.3 \pm 0.8$ \\
\hline dose length product $\left(\mu \mathrm{Gym}^{2}\right)$ & $5.3 \pm 1.3$ & $8.8 \pm 3.9$ & $3.2 \pm 0.9$ & $5.0 \pm 2$ \\
\hline effective dose $(\mathrm{mSv})$ & $0.4 \pm 0.11[0.33 / 0.49]$ & $0.5 \pm 0.2[0.32 / 0.58]$ & $0.27 \pm 0.071[0.22 / 0.29]$ & $0.27 \pm 0.1^{1}[0.24 / 0.36]$ \\
\hline SSDE (mGy) & $0.8 \pm 0.16[0.67 / 0.86]$ & $1.05 \pm 0.34[0.85 / 1.23]$ & $0.54 \pm 0.15^{1}[0.44 / 0.58]$ & $0.68 \pm 0.261[0.58 / 0.86]$ \\
\hline SNR & $24 \pm 9[18.6 / 29.7]$ & $25 \pm 14[14.9 / 27.8]$ & $15 \pm 7[10.6 / 16.3]$ & $16 \pm 8[12.4 / 19.1]$ \\
\hline CNR & $21 \pm 8[15.4 / 26.3]$ & $21 \pm 13[12.5 / 24.7]$ & $13 \pm 6[10.0 / 14.6]$ & $15 \pm 8[10.7 / 17.6]$ \\
\hline $\begin{array}{l}\text { visibility } \\
\text { of mammary artery }(\%)\end{array}$ & 90.1 & 88 & 100 & 79 \\
\hline $\begin{array}{l}\text { contrast medium used } \\
\text { (300 mg iodine/ml) }\end{array}$ & $2 \mathrm{ml} / \mathrm{kg}$ & $2 \mathrm{ml} / \mathrm{kg}$ & $2 \mathrm{ml} / \mathrm{kg}$ & $2 \mathrm{ml} / \mathrm{kg}$ \\
\hline
\end{tabular}

${ }^{1}$ Significant reduction between $2^{\text {nd }}$ and $3^{\text {rd }}$ generation DSCT $(p<0.0001)$. 
Table 2 Group-specific evaluation of image quality (number (portion of individual anatomical regions in percent)).

\begin{tabular}{|c|c|c|c|c|}
\hline & no artefacts & $\begin{array}{l}\text { fully interpretable } \\
\text { with minor artefacts }\end{array}$ & $\begin{array}{l}\text { still interpretable with regard } \\
\text { to the visibility of fine vascular } \\
\text { structures despite artefacts }\end{array}$ & $\begin{array}{l}\text { not interpreta- } \\
\text { ble }\end{array}$ \\
\hline all $(n=124)$ & $75(60.5 \%)$ & $46(37.1 \%)$ & $3(2.4 \%)$ & $0(0 \%)$ \\
\hline $\begin{array}{l}\text { complex transposition of major } \\
\text { arteries }(n=24)\end{array}$ & $14(58.3 \%)$ & $9(37.5 \%)$ & $1(4.2 \%)$ & $0(0 \%)$ \\
\hline aortic arch anomaly $(n=45)$ & $33(73.3 \%)$ & $11(24.4 \%)$ & $1(2.3 \%)$ & $0(0 \%)$ \\
\hline pulmonary artery/vein anomaly $(n=28)$ & $13(46.4 \%)$ & $14(50 \%)$ & $1(3.6 \%)$ & $0(0 \%)$ \\
\hline complex ventricular anatomy $(n=17)$ & $10(58.8 \%)$ & $7(41.2 \%)$ & $0(0 \%)$ & $0(0 \%)$ \\
\hline $\begin{array}{l}\text { total anomalous pulmonary venous } \\
\text { connection }(n=6)\end{array}$ & $4(66.7 \%)$ & $2(33.3 \%)$ & $0(0 \%)$ & $0(0 \%)$ \\
\hline other $(n=4)$ & $1(25 \%)$ & $3(75 \%)$ & $0(0 \%)$ & $0(0 \%)$ \\
\hline
\end{tabular}

\begin{tabular}{|llll|}
\hline parameter & results for neonates & results for infants & all results \\
\hline SNR, non-iterative & $15 \pm 7$ & $16 \pm 8$ & $16 \pm 8[9.2 / 18.6]$ \\
\hline SNR, iterative & $33 \pm 17$ & $30 \pm 15$ & $32 \pm 16[18.0 / 40.1]$ \\
\hline SNR increase (in \%) & $120 \%$ & $88 \%$ & $100 \% 1$ \\
\hline CNR, non-iterative & $13 \pm 6$ & $15 \pm 8$ & $14 \pm 7[8.2 / 17.0]$ \\
\hline CNR iterative & $29 \pm 14$ & $27 \pm 14$ & $29 \pm 15[14.6 / 35.3]$ \\
\hline CNR increase (in \%) & $123 \%$ & $80 \%$ & $107 \%^{2}$ \\
\hline
\end{tabular}

Table 3 Increase of signal-tonoise-ratio (SNR) and contrast-tnoise-ratio (CNR) due to iterative reconstruction of image data $3^{\text {rd }}$ generation DSCT (number or mean score \pm standard deviation) and $\left[1^{\text {st }} / 3^{\text {rd }}\right.$ quartile $]$.

${ }^{1}$ significant increase through iteration $(p<0.0011)$ :

2 significant increase through iteration $(\mathrm{p}<0.0034)$ :

\begin{tabular}{|c|c|c|c|c|c|}
\hline & essential & very helpful & helpful & not helpful & misleading \\
\hline all $(n=124)$ & $24(19.4 \%)$ & $84(67.7 \%)$ & $16(12.9 \%)$ & $0(0 \%)$ & $0(0 \%)$ \\
\hline $\begin{array}{l}\text { complex transposition of } \\
\text { major arteries }(n=24)\end{array}$ & $4(16.7 \%)$ & $17(70.8 \%)$ & $3(12.5 \%)$ & $0(0 \%)$ & $0(0 \%)$ \\
\hline aortic arch anomaly $(n=45)$ & $8(17.8 \%)$ & $29(64.4 \%)$ & $8(17.8 \%)$ & $0(0 \%)$ & $0(0 \%)$ \\
\hline pulmonary artery/vein anomaly $(n=28)$ & $4(14.3 \%)$ & $20(71.4 \%)$ & $4(14.3 \%)$ & $0(0 \%)$ & $0(0 \%)$ \\
\hline complex ventricular anatomy $(n=17)$ & $5(29.4 \%)$ & $11(64.7 \%)$ & $1(5.9 \%)$ & $0(0 \%)$ & $0(0 \%)$ \\
\hline $\begin{array}{l}\text { total anomalous pulmonary venous } \\
\text { connection }(n=6)\end{array}$ & $3(50 \%)$ & $3(50 \%)$ & $0(0 \%)$ & $0(0 \%)$ & $0(0 \%)$ \\
\hline other $(n=4)$ & $0(0 \%)$ & $4(100 \%)$ & $0(0 \%)$ & $0(0 \%)$ & $0(0 \%)$ \\
\hline
\end{tabular}

Table 4 Group-specific evaluation of surgical value using a LikertScale. Number (portion of individual anatomical regions in percent).

DSCT, the increase in objective quality through iterative reconstruction was computed and evaluated (see 0 Table 3 ).

To further analyze the resolution of fine vascular structures, a slab of the anterior thoracic wall was visualized in maximal intensity projection (MIP) and the visibility of the mammary artery was assessed. The parameters SNR and CNR were computed for objective analysis of image quality. For this purpose, median signal intensity was measured at different sites in the vascular lumen (ascending aorta, descending aorta, pulmonary artery) as well as in the autochthonous muscles of the back. The image noise is defined by the standard deviation of the signal intensity in the ambient air. SNR is computed from the quotient of the median in the vascular lumen and the image noise. The CNR is computed from the difference of the median value of the vascular lumen and the autochthonous muscles of the back, divided by the image noise.

During the surgical planning conference, the 3D-image data was presented by a pediatric cardiologist to the cardiac surgery team directly on the TeraRecon workstation to precisely clarify the specific anatomical situation, and specific questions posed were answered immediately using appropriate visualization. The benefits resulting for the surgical intervention planning were evaluated by the surgeon using a 5-point Likert scale following surgery [19]. Datasets were rated as "essential" if the surgeries as performed would not have been possible without the information obtained from DSCT. Datasets delivering, in addition to the always available echocardiographic image data, important information that positively influenced the surgery were rated as "very useful". Datasets were rated as "useful", if they provided useful information in addition to that obtained from echocardiography, but did not impact the surgery. Datasets not providing any additional useful information were rated as "not useful". Datasets presenting erroneous or misleading information were rated as "misleading". To individually evaluate the use of DSCT for different heart defects, the patient cohort was divided into five groups based anatomical features, and the surgical benefits were presented according to group ( $\bullet$ Table 4 ).

The volume CT dose index (CTDIvol) and dose length product (DLP) were used in computing radiation exposure. The effect dose was computed from the DLP and the age-specific conversion factor according to Deak et al. (0.0832 for neonates, 0.0525 for children under one year of age) [20]. The age-specific conversion factor was used for the $70 \mathrm{kV}$ and 
$80 \mathrm{kV}$ setting. A size-correlated assessment of radiation exposure was performed by computing the size-specificdose-estimate (SSDE) ( $\bullet$ Table 1 ), which is the product of CTDIvol and a thoracic diameter-specific correction factor for the $32 \mathrm{~cm}$ phantom. For this purpose, anterior-posterior as well as lateral thoracic diameter were measured in the slice plane in which all 4 heart chambers could be well evaluated [21].

\section{Results}

In this study, we used $2^{\text {nd }}$ generation DSCT in 91 cases and $3^{\text {rd }}$ generation DSCT in 27 cases for diagnosing cardiac patients less than one year old. Demographic and procedural data were evaluated and presented as medians plus standard deviation ( $\bullet$ Table 1$)$. All examinations were performed free of problems and without any side effects being observed.

All of the obtained datasets were interpretable. The individual results for image quality analysis were as follows: "no artifacts" in 75 cases (60.5\%), "fully interpretable with minor artifacts" in 46 cases (37.1\%) and "interpretable regarding the visibility of fine vascular structures despite artifacts" in 3 cases (2.4\%) ( $\diamond$ Table 2 ). The mammary artery was visible to the diaphragmatic arch at MIP in over $80 \%$ of cases. SNR and CNR were computed for objective assessment of image quality. For examinations performed with $2^{\text {nd }}$ generation DSCT, median SNR was 25, while median CNR was 21. For examinations performed with $3^{\text {rd }}$ generation DSCT, the computed parameters were lower than those of $2^{\text {nd }}$ generation DSCT with a median SNR of 16 and a median CNR of 14 . To increase the image quality for $3^{\text {rd }}$ generation DSCT, advanced modelled iterative reconstruction (ADMIRE) was performed ( $\bullet$ Fig. 1), thereby boosting the parameters SNR by $100 \%$ to 32 and CNR by $107 \%$ to 29 ( $\bullet$ Table 3 ).

In all cases, the image data obtained from the DSCT examination was rated to be helpful for surgical planning and its diagnostic value exceeded that of conventional echocardiography ("essential”, "very useful”, “useful”). The individual results for the $2^{\text {nd }}$ and $3^{\text {rd }}$ generation DSCT were as follows: essential in $24(19.4 \%)$ cases, very useful in $84(67.7 \%)$ cases, useful in $16(12.9 \%)$ cases. There were no instances of the information not being useful or yielding misleading results ( $\bullet$ Table 4$)$.

With $2^{\text {nd }}$ generation DSCT, the computed median radiation exposure was $0.4 \mathrm{mSv}$ for neonates and $0.5 \mathrm{mSv}$ for infants. By reducing tube voltage from $80 \mathrm{kV}$ to $70 \mathrm{kV}$ and using more advanced X-ray tubes, as well as employing iterative reconstruction, we were able in this study to achieve with $3^{\text {rd }}$ generation DSCT a median effective dose of $0.27 \mathrm{mSv}$ and thus a significant dose reduction $(\mathrm{p}<0.0001)$ for both neonates and infants while at the same time preserving image quality. This corresponds to a reduction of effective dose of $32.5 \%$ for neonates and $46 \%$ for infants. Accordingly, the SSDE was significantly lower for $3^{\text {rd }}$ generation DSCT (0.55 mGy) than it was for $2^{\text {nd }}$ generation $(0.85 \mathrm{mGy})$.

\section{Discussion \\ $\nabla$}

In our study, we retrospectively evaluated 118 preoperative CT examinations in terms of image quality, radiation exposure as well as use and predictive value in surgical planning. In $87.1 \%$ of cases helpful information for heart surgery was obtained in addition to the existing echocardiographic findings. In $19.4 \%$ of cases, the examination was even rated as

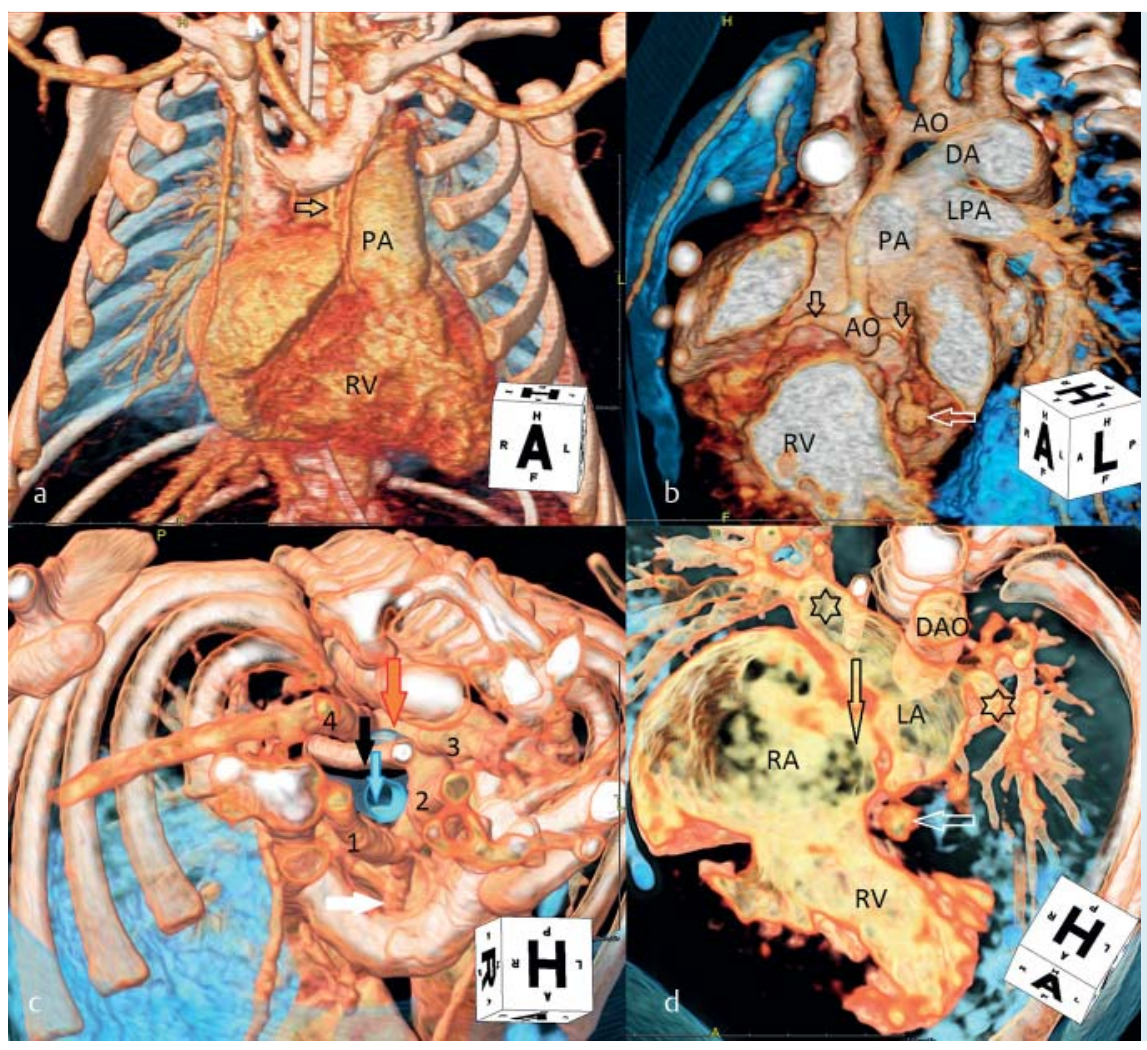

Fig. 2 Second generation angiographic DualSource-CT of a 5-day old boy with hypoplastic left heart syndrome (HLHS) with aortic atresia and aberrant departure of the right subclavian artery as the last branch of the aortic arch (A. lusoria). Figure a demonstrates the situs with its delicate ascending aorta (arrow), the main pulmonary artery (PA) and large right ventricle. Figure $\mathbf{b}$ shows the hypoplastic left ventricle (white arrow) and hypoplastic ascending aorta $(\mathrm{AO})$ with retrograde perfusion being employed to supply the coronary arteries (black arrows). The large ductus arteriosus (DA) connects the pulmonary artery and the aorta after the branching of left pulmonary artery. Figure $\mathbf{c}$ shows the aortic arch from a cranial view. The white arrow marks the ascending aorta, $1=$ right common carotid artery, 2 = left common carotid artery, $3=$ left subclavian artery, 4 = aberrant right subclavian artery (A. lusoria). Red arrow = descending aorta, black arrow $=$ nasogastric feeding tube, blue arrow $=$ trachea. Figure $\mathbf{d}$ shows a sectional view of the large right atrium (RA) and left atrium (LA). Right and left atriums are both connected by the narrow foramen ovale (black arrows). Pulmonary veins (stars), hypoplastic left ventricle (white arrow) and descending aorta (DAO) are shown. 


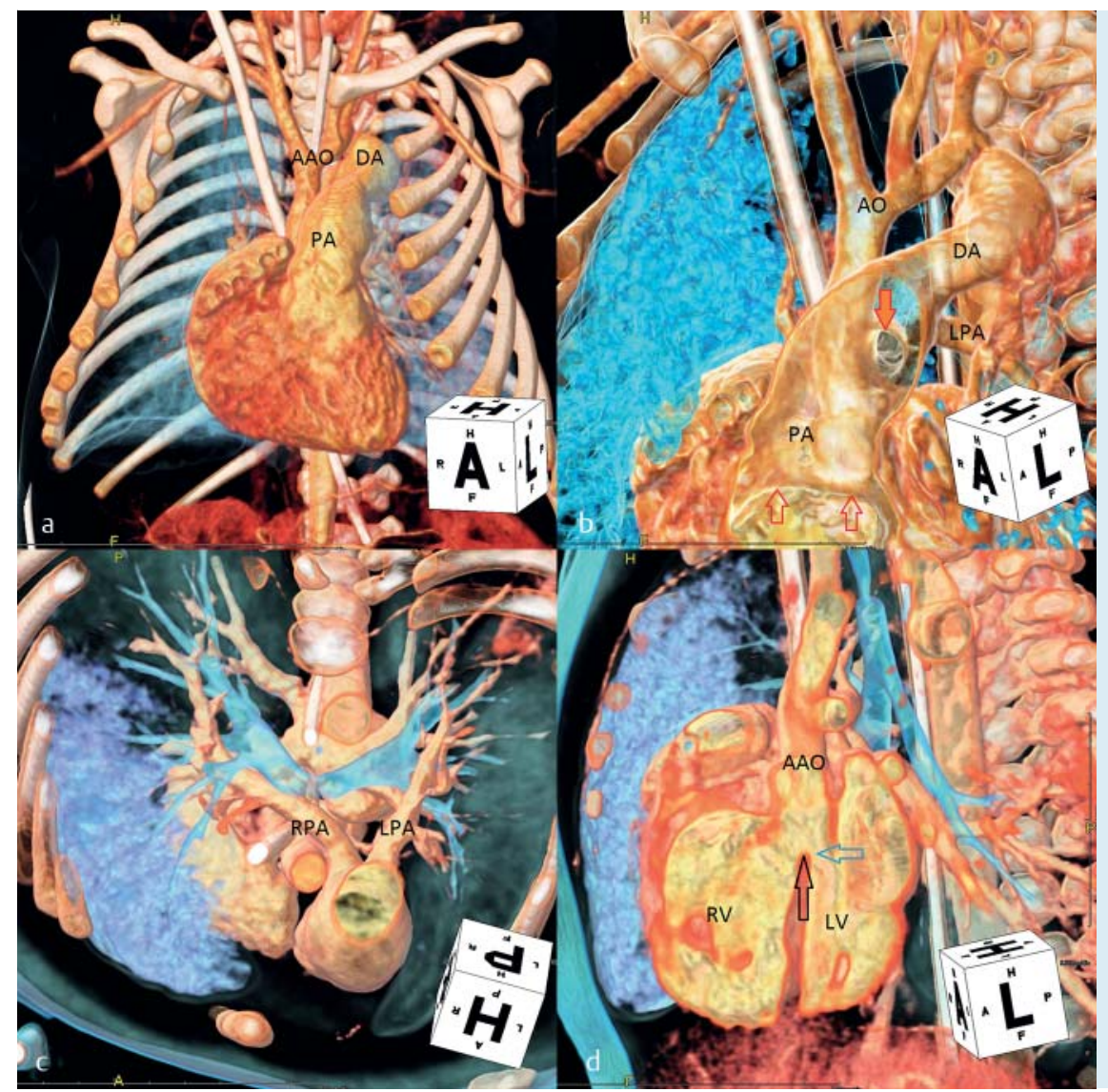

Fig. 3 Third generation angiographic Dual-SourceCT of a two-day old newborn with ductus-dependent body perfusion, hypoplastic aortic arch, subaortic ventricular septal defect, stenosis of left ventricular outflow tract and hypoplastic peripheral pulmonary arteries. Figure a shows the situs and the hypoplastic ascending aorta (AAO), outsized main pulmonary artery (PA) and large ductus arteriosus (DA). Figure $\mathbf{b}$ shows the major arteries, $\mathrm{AO}=$ aorta which is hypoplastic up to the connection with the descending aorta, $\mathrm{PA}=$ main pulmonary artery with large diameter. Solid red arrow $=$ departure of right pulmonary branch. Empty red arrows $=$ pulmonary valve. Figure $\mathbf{c}$ shows the cranial view of hypoplastic right pulmonary branch (RPA) and left pulmonary branch (LPA). Figure $\mathbf{d}$ displays the right (RV) and left ventricle (LV) as well as the aorta (AAO) which overrides the ventricular septal defect (black arrow). Blue arrow = obstructive left ventricular outflow tract.
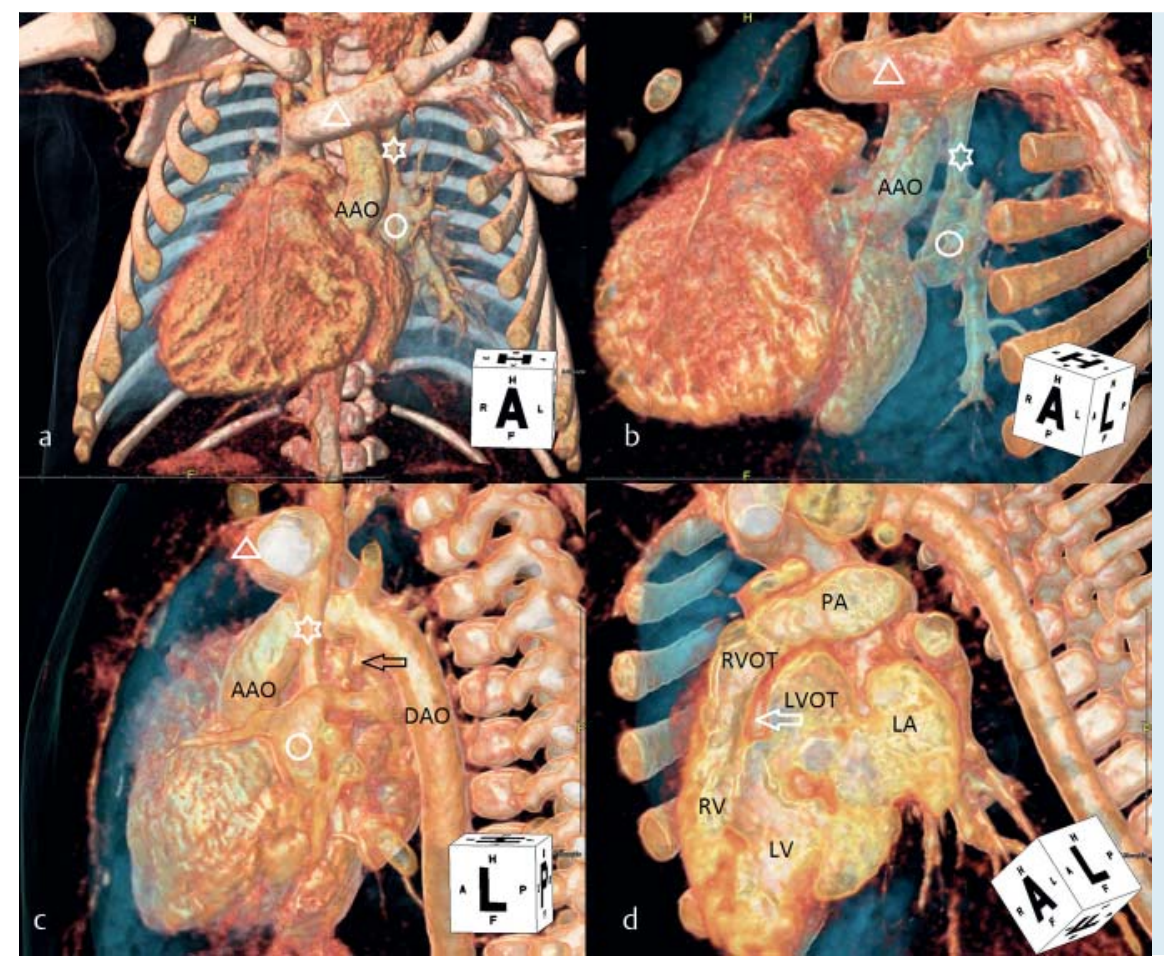

Fig. 4 Third generation angiographic Dual-SourceCT of a three-day old newborn with heterotaxy syndrome and total anomalous pulmonary venous connection. Figure a shows the dextrocardia, $\mathrm{AAO}=$ ascending aorta, the circle marks the confluence of the pulmonary veins and the star shows the common pulmonary vein that leads to the innominate vein (triangle). Figure $\mathbf{b}$ clearly demonstrates in a left-lateral angulation the confluence of the pulmonary veins (circle), the common pulmonary vein (star), which is centrally obstructed, and the innominate vein (triangle). Using the same symbols figure $\mathbf{c}$ demonstrates the spatial relation of anomalous pulmonary venous connection and aorta ( $\mathrm{AAO}=$ ascending aorta, $\mathrm{DAO}=$ descending aorta). The residual ductus arteriosus is marked by an arrow. Figure $\mathbf{d}$ shows a modified sagittal section through the heart. RV = hypoplastic, right ventricle lying anterior, RVOT = right ventricular outflow tract separated from the left ventricular outflow tract by a muscle cone (arrow), LV = left ventricle, above the $L A=$ left atrium

being "essential" for surgical planning, and the obtained information decisively influenced further therapeutic procedure. The image data was of diagnostic use in all cases. Decidedly extracardiac structures such as aortic arches and pulmonary arteries ( $\bullet$ Fig. 2, 3), pulmonary veins ( $\bullet$ Fig.4), pathological extracardiac vessels and coronary arteries as well as their spatial relation to the airways ( $\bullet$ Fig. 5) can be precisely and comprehensively presented. The superiority of this modality over echocardiography is especially apparent here as it likewise is in the visualization of the spatial re- 


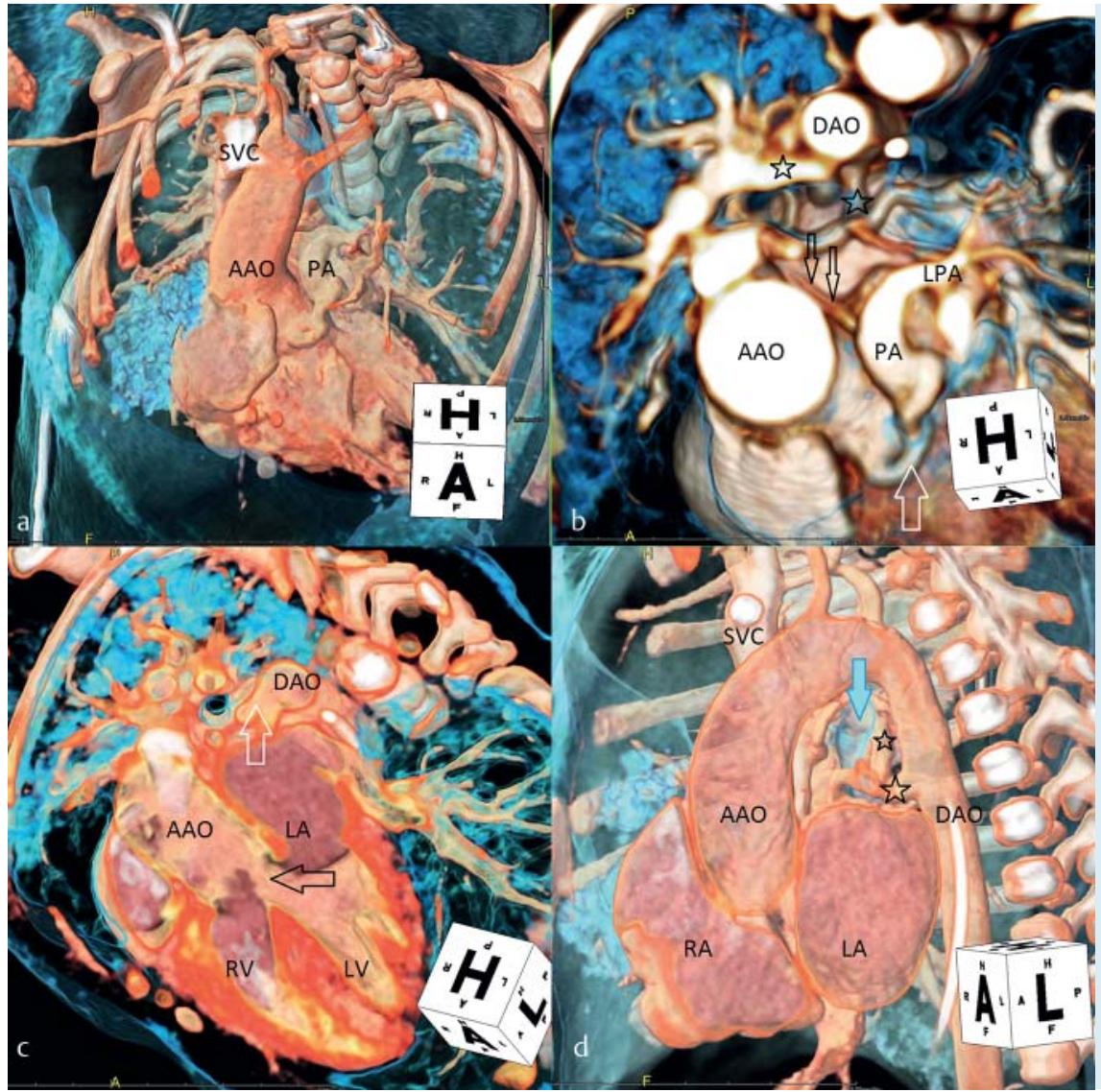

Fig. 5 Third generation angiographic Dual-SourceCT of a two day-old boy with pulmonary atresia and ventricular septal defect (VSD) as well as a fistula between right coronary artery and pulmonary trunk. Figure a shows the situs, $A A O=$ ascending aorta, PA = hypoplastic pulmonary artery, SVC = superior vena cava. Figure $\mathbf{b}$ : There is a connection between the right coronary artery (white arrow) and central pulmonary artery (PA). The left pulmonary artery (LPA) is well developed, the right pulmonary artery appears as delicate structure in the central area (black arrows). There are two main aortopulmonary collateral arteries (MAPCA) (stars) originating anterior from the descending aorta (DAO). Figure $\mathrm{c}$ shows the aorta (AAO) overriding the VSD. Both the right and left ventricle are formed correctly. The MAPCAs (stars) originate from the descending aorta (DAO). Figure $\mathbf{d}$ illustrates the right-sided aortic arch and the spatial relationship of the aortopulmonary collaterals (stars) to the right main bronchus (blue arrow). RA = right atrium, $\mathrm{LA}=$ left atrium, SVC = superior vena cava.

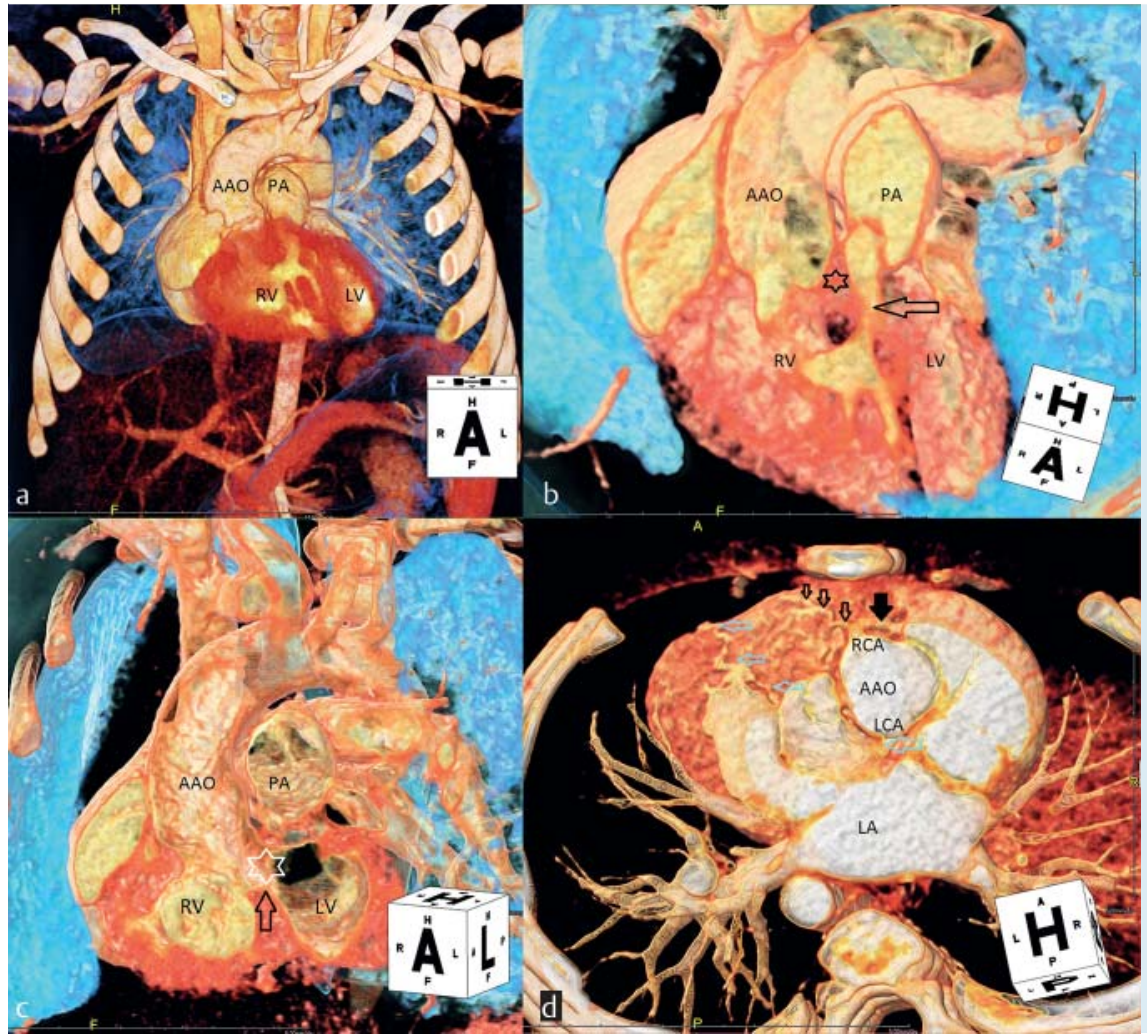

Fig. 6 Third generation angiographic Dual-SourceCT of a two-month old boy with Double Outlet Right Ventricle (DORV), malposition of the great arteries, subpulmonary stenosis and strong cone branch of the right coronary artery above the right ventricular outflow tract. Figure a shows the situs with the aorta situated right anterior (AAO) and pulmonary artery (PA) to its left. The origin of the two great arteries from the right ventricle (RV) is demonstrated in Figure $\mathbf{b}$. The star marks the muscular cone between right and left ventricular outflow tracts, which causes the subpulmonary stenosis (arrow) on the right-lateral side. Figure $\mathbf{c}$ shows the aorta (AAO) arising from the right ventricle (RV), the ventricular septal defect is marked by the white star, and the black arrow shows the top of ventricular septum. This visualization enables surgical planning for tunneling of the left ventricle (LV) to the aorta. $\mathrm{PA}=$ pulmonary trunk. Figure $\mathbf{d}$ shows the origin of the coronary arteries from the aorta. Left coronary artery (LCA) originates dorsally, and the further course of the ramus interventricularis is marked by blue arrows. Right coronary artery originates from the anterior (RCA, filled black arrow). Empty arrows show the course of the cone branch over the right ventricular outflow tract, which required an extra-anatomical correction to resolve the subpulmonary stenosis. 
lation between intracardiac structures and the extracardiac vessels in an individual dataset ( $\bullet$ Fig. 6 ). Using $3^{\text {rd }}$ generation DSCT allowed radiation exposure to be reduced on average by $41 \%$ to a median effective dose of $0.27 \mathrm{mSv}$ ( $p<0.0001$ ), with SSDE correspondingly being reduced significantly. The advanced modelled iterative reconstruction employed in this process facilitated a clear, significant increase in image quality. While reducing tube voltage with $3^{\text {rd }}$ generation DSCT to $70 \mathrm{kV}$ resulted, as expected, in increased image noise, SNR and CNR at $80 \mathrm{kV}$ acquisition were clearly higher for FBP. This may be attributed to the different generations of CT machines having differing tubes and detectors. The use of iterative reconstruction (ADMIRE4) caused SNR and CNR to rise significantly with $3^{\text {rd }}$ generation DSCT.

Pediatric cardiac surgeons are often confronted with complex anatomies. Severe heart defects are frequently corrected in highly complicated surgeries. The risk of complications increases with time spent on heart-lung machines $[22,23]$. To minimize this risk, surgery must be as brief as possible. To keep surgical trauma as low as possible and to facilitate a strictly forward-moving surgery, the surgical team should be thoroughly acquainted with the anatomical situation. By allowing spatial relations and precise anatomy to be gathered independently of the highly variable individual perception, adequate $3 \mathrm{D}$ imaging of the intracardiac and extracardiac structures is essential for optimal planning and execution of surgery [24]. As the diagnostic gold standard for congenital heart defects, echocardiography is often limited, in complicated cases, by the poor acoustic window and the compromised visibility of extracardiac structures.

In 2005, Flohr et al. documented initial clinical experience with the new technology of dual-source-computed tomography in cardiology [26]. In 2006, Lee et al. presented the potential application of DSCT in neonates with congenital heart defects in the first clinical study. DSCT was used in supplement to echocardiography and increasingly replaced invasive heart catheter examination for certain clinical questions [10].

Because children are more vulnerable than adults to X-ray radiation [27], reducing radiation exposure in CT exams is therefore a key goal of technological progress. In their 2009 study involving 110 children under one year of age with congenital heart defects, Ben Saad et al. performed DSCT examinations. They used the Siemens Somatom Definition Flash at the $80 \mathrm{kV}$ setting, with good diagnostic quality being obtained in $89 \%$ of cases. The median effective dose was $0.5 \mathrm{mSv}$ for the non-ECG-triggered CT and $1.3 \mathrm{mSv}$ for the ECG-triggered CT [17]. In comparison, good diagnostic value was yielded in all cases in our study. With the aid of $3^{\text {rd }}$ generation DSCT, we were able to achieve a clearly lower median effective dose with less than $0.3 \mathrm{mSV}$. In their study, Yoon et al. examined the influence of reconstruction by means of "adaptive statistical iterative reconstruction" (ASIR) on radiation dose and image quality when using DSCT. The age of patients with congenital heart defects ranged between 0.1 and 17 years. A 64-line CT (Somatom Definition Flash, Siemens) was used. In the ASIR group, a tube voltage of $100 \mathrm{kV}$ was used for patients weighing over $40 \mathrm{~kg}$, while $80 \mathrm{kV}$ was used for patients weighing below $40 \mathrm{~kg}$. In the control group, a $120 \mathrm{kV}$ setting was used for patients weighing above $40 \mathrm{~kg}$. Using iterative reconstruction allowed the median effective dose to be lowered by $57 \%$ from $4.1 \mathrm{mSv}$ to $1.7 \mathrm{mSv}$ without any significant penalty in image quality [28]. In our study, we achieved a median dose reduction of $32.4 \%$ among newborns and $45 \%$ among infants with clearly lower starting values using advanced modelled iterative reconstruction of $3^{\text {rd }}$ generation DSCT.

Küttner et al. already recommended DSCT as a diagnostic alternative for neonates, children and adolescents with congenital heart defects. They emphasized the advantage of iterative reconstruction, which allows a significant reduction in radiation exposure. They used a 64-line CT. Median patient age was 14 years. In their study, they achieved a median effective dose of 0.6 to $3.2 \mathrm{mSv}$ [9]. Because of the growing experience with and use of $3^{\text {rd }}$ generation DSCT, we were able to achieve clearly lower radiation exposure among our patients with values ranging between 0.26 and $0.5 \mathrm{mSv}$. In their study, Singh et al. demonstrated that a significant dose reduction is possible with the aid of IR. The dose was lowered by $46.4 \%$ (3.7 vs. $6.9 \mathrm{mGy}$ ) when ASIR was employed. This particular study used a 64-slice $\mathrm{CT}$, and the median age of the patients examined was 12 years [29]. Hou Y. et al. likewise examined the possibility of dose reduction through the use of iterative reconstruction. For this purpose, they performed coronary CTA on 110 patients with an average age of $54 \pm 10$ years using a 256-line MDCT (Brilliance iCT, Philips). Tube voltage was $120 \mathrm{kV}$ for all groups. The control group was examined with $210 \mathrm{mAs}$ in FBP. In all other groups, tube current was incrementally reduced to $65 \mathrm{mAs}$, and the increasing image noise was compensated through iterative reconstruction. In this study, the effective dose was decreased by $63 \%$ from $3.2 \pm 0.6 \mathrm{mSv}$ to $1.2 \pm 0.1 \mathrm{mS}$ by using IR and reducing tube voltage, while excellent image quality was maintained.

\section{Conclusion \\ $\nabla$}

Cardiac surgical interventions are highly complicated and require optimal planning. With high-resolution 3D-datasets and advanced visualization technology, DSCT provides the entire surgical team with comprehensive and tangible information on the patient's complex thoracic anatomy, while allowing the effective dose to consistently be kept below $0.5 \mathrm{mSv}$. Modern DSCT is an adequate preoperative imaging modality for neonates and infants with complex congenital heart defects when echocardiography is unable to comprehensively clarify the anatomical situation.

\section{Limitations \\ $\nabla$}

The assessment of image quality and surgical benefits using a Likert scale cannot be completely objective and is performed by a cardiologist and surgeon, respectively.

Because the conversion factors for converting the effective dose are not yet available for $70 \mathrm{kV}$, the conversion was performed using conversion factors for $80 \mathrm{kV}$.

The present work was performed in fulfillment of the requirements for obtaining the degree "Dr. med". 


\section{List of abbreviations}

3 D Three-dimensional

ADMIRE Advanced Modeled Iterative Reconstruction

ASIR Adaptive Statistical Iterative Reconstruction

CNR Contrast-to-noise ratio

CT Computed tomography

CTDIvol Volume CT dose index

MDCT Multi-detector computed tomography

DLP Dose length product

DSCT Dual source computed tomography

EKG Electrocardiography

FBP Filtered back projection

HCE Heart catheter examination

IR Iterative reconstruction

MIP Maximum intensity projection

MRI Magnetic resonance imaging

SNR Signal-to-noise ratio

SSDE Size-specific dose estimates

\section{References}

1 Lindinger A, Schwedler G, Hense HW. Prevalence of Congenital Heart Defects in Newborns in Germany: Results of the First Registration Year of the PAN Study (July 2006 to June 2007). Klin Padiatr 2010; 222: $321-326$

2 Silva KP, Rocha LA, Leslie AT et al. Newborns with congenital heart diseases: epidemiological data from a single reference center in Brazil. J Prenat Med 2014; 8: 11 -16

3 Schultz AH, Localio AR, Clark BJ et al. Epidemiologic features of the presentation of critical congenital heart disease: implications for screening. Pediatrics 2008; 121: $751-757$

4 Tumanyan MR, Filaretova OV, Chechneva VV et al. Repair of Complete Atrioventricular Septal Defect in Infants with Down Syndrome: Outcomes and Long-Term Results. Pediatr Cardiol 2014; DOI: 10.1007/ s00246-014-0966-7

5 Padalino MA, Cavalli G, De Franceschi M et al. Surgical outcomes of total anomalous pulmonary venous connection repair: a 22-year experience. J Card Surg 2014; 29: 678 -685

6 Nakayama Y, Hiramatsu T, Iwata Y et al. Surgical results for functional univentricular heart with total anomalous pulmonary venous connection over a 25-year experience. Ann Thorac Surg 2012; 93: 606-613

7 Glöckler M, HalbfaßJ, Koch A et al. Preoperative assessment of the aortic arch in children younger than 1 year with congenital heart disease: utility of low-dose high-pitch dual-source computed tomography. A single-centre, retrospective analysis of 62 cases. Eur J Cardiothorac Surg 2014; 45: 1060-1065

8 Bharucha T, Mertens L. Recent advances in pediatric echocardiography. Expert review of cardiovascular therapy 2013; 11: $31-47$

9 Kuettner A, Gehann B, Spolnik J et al. Strategies for dose-optimized imaging in pediatric cardiac dual source CT. RoFo: Fortschritte auf dem Gebiete der Rontgenstrahlen und der Nuklearmedizin 2009; 181: 339 348

10 Lee T, Tsai IC, Fu YC et al. Using multidetector-row CT in neonates with complex congenital heart disease to replace diagnostic cardiac catheterization for anatomical investigation: initial experiences in technical and clinical feasibility. Pediatr Radiol 2006; 36: 1273-1282

11 Achenbach S, Barkhausen J, Beer $M$ et al. Consensus recommendations of the German Radiology Society (DRG), the German Cardiac Society (DGK) and the German Society for Pediatric Cardiology (DGPK) on the use of cardiac imaging with computed tomography and magnetic resonance imaging. Fortschr Röntgenstr 2012; 184: 345-368
12 Achenbach S, Barkhausen J, Beer $M$ et al. Consensus recommendations of the German Radiology Society (DRG), the German Cardiac Society (DGK) and the German Society for Pediatric Cardiology (DGPK) on the use of cardiac imaging with computed tomography and magnetic resonance imaging. Fortschr Röntgenstr 2012; 184: 345 - 368

13 Khatri S, Varma SK, Khatri P et al. 64-slice multidetector-row computed tomographic angiography for evaluating congenital heart disease. Pediatr Cardiol 2008; 29: 755-762

14 Ou P, Celermajer DS, Calcagni G et al. Three-dimensional CT scanning: a new diagnostic modality in congenital heart disease. Heart 2007; 93: 908-913

15 Taylor AM, Dymarkowski S, Hamaekers $P$ et al. MR coronary angiography and late-enhancement myocardial MR in children who underwent arterial switch surgery for transposition of great arteries. Radiology 2005; 234: $542-547$

16 Glockler M, Halbfass J, Koch A et al. Preoperative assessment of the aortic arch in children younger than 1 year with congenital heart disease: utility of low-dose high-pitch dual-source computed tomography. A single-centre, retrospective analysis of 62 cases. European journal of cardio-thoracic surgery 2014; 45: 1060-1065

17 Ben Saad M, Rohnean A, Sigal-Cinqualbre A et al. Evaluation of image quality and radiation dose of thoracic and coronary dual-source CT in 110 infants with congenital heart disease. Pediatr Radiol 2009; 39: $668-676$

18 Bongartz GGS, Jurik AG, Leonardi M et al. European Guidelines on Quality Criteria for Computed Tomography; 2015, Accessed february 18 2015

19 Ellis AR, Mulvihill D, Bradley SM et al. Utility of computed tomographic angiography in the pre-operative planning for initial and repeat congenital cardiovascular surgery. Cardiology in the young 2010; 20 : $262-268$

20 Deak PD, Smal Y, Kalender WA. Multisection CT protocols: sex- and age-specific conversion factors used to determine effective dose from dose-length product. Radiology 2010; 257: 158-166

21 Brady SL, Kaufman RA. Investigation of American Association of Physicists in Medicine Report 204 size-specific dose estimates for pediatric CT implementation. Radiology 2012; 265: 832 - 840

22 Shinkawa T, Anagnostopoulos PV, Johnson NC et al. Early results of the "clamp and sew" Fontan procedure without the use of circulatory support. Ann Thorac Surg 2011; 91: 1453-1459

23 Navabi MA, Rastegar SM, Kiani A et al. Avoiding cardiopulmonary bypass in extracardiac cavopulmonary connection: does it really matter? J Thorac Cardiovasc Surg 2010; 139: 1183-1188

24 Chen X, Qu Y, Peng ZY et al. Clinical value of multi-slice spiral computed tomography angiography and three-dimensional reconstruction in the diagnosis of double aortic arch. Experimental and therapeutic medicine 2014; 8: 623-627

25 Mertens L, Seri I, Marek J et al. Targeted neonatal echocardiography in the neonatal intensive care unit: practice guidelines and recommendations for training. Eur J Echocardiogr 2011; 12: 715-736

26 Flohr TG, McCollough CH, Bruder $\mathrm{H}$ et al. First performance evaluation of a dual-source CT (DSCT) system. European radiology 2006; 16: $256-268$

27 Brenner DJ, Hall EJ. Computed tomography - an increasing source of radiation exposure. N Engl J Med 2007; 357: 2277-2284

28 Yoon H, Kim MJ, Yoon CS et al. Radiation dose and image quality in pediatric chest CT: effects of iterative reconstruction in normal weight and overweight children. Pediatr Radiol 2014; DOI: 10.1007/s00247014-3176-9

29 Singh S, Kalra MK, Shenoy-Bhangle AS et al. Radiation dose reduction with hybrid iterative reconstruction for pediatric CT. Radiology 2012; 263: $537-546$

$30 \mathrm{Hou} Y, X u$ S, Guo W et al. The optimal dose reduction level using iterative reconstruction with prospective ECG-triggered coronary CTA using 256-slice MDCT. European journal of radiology 2012; 81: 3905-3911 